\title{
Tensiometria e balanço hídrico climatológico no manejo de irrigação do feijão-caupi “BRS Pujante
}

\author{
Tensiometry and climatological water balance in the irrigation management of \\ cowpea "BRS Pujante"
}

\author{
RODRIGUES, Joerlandes de Sousa. Graduação/Engenharia Agronômica \\ Instituto Federal de Educação, Ciência e Tecnologia do Sertão Pernambucano - Campus Petrolina Zona Rural. Rodovia \\ PE-647, Km 22, PISNC N - 4, Zona Rural - Petrolina - PE - Brasil. CEP: 56.302-970 / Telefone: (87) 2101-8050, e-mail: \\ joerlandes@hotmail.com
}

\section{SILVA, Maria Gilzete Guimarães da. Graduação/Engenharia Agronômica}

Instituto Federal de Educação, Ciência e Tecnologia do Sertão Pernambucano - Campus Petrolina Zona Rural. Rodovia PE-647, Km 22, PISNC N - 4, Zona Rural - Petrolina - PE - Brasil. CEP: 56.302-970 / Telefone: (87) 2101-8050, e-mail: mariangilzete@gmail.com

\section{SOUSA, José Sebastião Costa de. Doutor/Engenharia Agrícola}

Instituto Federal de Educação, Ciência e Tecnologia do Sertão Pernambucano - Campus Petrolina Zona Rural. Rodovia PE-647, Km 22, PISNC N - 4, Zona Rural - Petrolina - PE - Brasil. CEP: 56.302-970 / Telefone: (87) 2101-8050, e-mail: sebastiao.costa@ifsertao-pe.edu.br

\section{SIMÕES, Welson Lima. Doutor/Engenharia Agronômica}

Embrapa Semiárido, Rodovia BR-428, Km 152, Zona Rural - Petrolina - PE - Brasil. CEP: 56.302-970, / Telefone: (87) 3866-3600, e-mail: welson.simoes@embrapa.br

\section{LORENZO, Vitor Prates. Doutor/Produtos Naturais e Sintéticos Bioativos}

Instituto Federal de Educação, Ciência e Tecnologia do Sertão Pernambucano - Campus Petrolina Zona Rural. Rodovia PE-647, Km 22, PISNC N - 4, Zona Rural - Petrolina - PE - Brasil. CEP: 56.302-970 / Telefone: (87) 2101-8050, e-mail: vitor.lorenzo@ifsertao-pe.edu.br

\section{RESUMO}

Objetivou-se com o presente trabalho avaliar a influência do controle da irrigação com tensiômetros e com o balanço hídrico climatológico da culturausando Kc dual (coeficiente de cultura duplo), nos atributos produtivos do feijão-caupi (Vignaunguiculata L. Walp.) CV. BRS Pujante. 0 trabalho foi realizado em Petrolina-PE, no delineamento experimental de blocos casualizados com dois tratamentos (manejo tensiométrico e balanço hídrico climatológico da cultura) e 12 repetições. Avaliou-se número de vagens por planta, comprimento de vagens, número de grãos por vagem, massa de cem grãos, produtividade total de grãos e eficiência no uso da água (EUA). Observou-sediferença significativa apenas para a EUA, que foi de 7,40 e 3,40 $\mathrm{kgmm}^{-1}$ ha-1 para o manejo tensiométrico e balanço hídrico climatológico da cultura, respectivamente. 0 uso de 183,75 mmde lâmina de irrigação com o manejo tensiométrico proporcionou uma economia de $55 \%$ no uso da água quando comparado com o manejo por balanço hídrico climatológico. A produtividade média da cultura foi de $1.454,68 \mathrm{~kg} \mathrm{ha}^{-1} \mathrm{com} 1.344,60^{\circ} \mathrm{C}$ de soma térmica.

Palavras-chave: Vignaunguiculata, produtividade, uso eficiente da água, $\mathrm{Kc}$ dual, soma térmica.

\begin{abstract}
The objective of this work was to evaluate the influence of irrigation control with tensiometers and the climatic water balance of the crop using dual Kc (double crop coefficient), on the productive attributes of cowpea (Vigna unguiculata L. Walp. ) cv. BRS Pujante. The work was carried out in Petrolina-PE, in the experimental design of randomized blocks with two treatments (tensiometric management and climatological water balance of the crop) and 12 replications. Number of pods per plant, pod length, number of grains per pod, mass of one hundred grains, total grain yield and water use efficiency (WUE) were evaluated. A significant difference was observed only for the WUE, which was 7.40 and $3.40 \mathrm{~kg} \mathrm{~mm}^{-1}$ $\mathrm{ha}^{-1}$ for the tensiometric management and climatological water balance of the crop, respectively. The use of a $183.75 \mathrm{~mm}$ irrigation blade with the tensiometric management provided a saving of $55 \%$ in water use when compared to the management by climatological water balance. The average yield of the crop was $1,454.68 \mathrm{~kg} \mathrm{ha}^{-1}$ with $1.344 .60^{\circ} \mathrm{C}$ of thermal sum.
\end{abstract}

keywords: Vigna unguiculata, productivity, water efficiency, dual Kc, thermal sum. 
RODRIGUES, J. S.; SILVA, M. G. G.; SOUSA, J. S. C.; SIMÕES, W. L.; LORENZO, V. P. Tensiometria e balanço hídrico climatológico no manejo de irrigação do feijão-caupi "BRS Pujante

\section{Introdução}

O feijão (Phaseolus vulgaris L., conhecido popularmente como feijão-comum,e Vigna unguiculata L.Walp., denominado de feijão-caupi ou feijão-de-corda ou ainda feijão-macassar) éum dos alimentos mais consumidos pelo brasileiro, e é a principal fonte vegetal de proteínas, carboidratos e minerais, especialmente o ferro (Azevedo et al., 2015; Gomes et al., 2017).

De acordo com os últimos dados da CONAB (Companhia Nacional de Abastecimento) o Brasil ocupa o terceiro lugar no ranque mundial de países produtores de feijão, tendo as regiões norte e nordeste como as mais expressivas (CONAB, 2018). Contudo, o país ainda apresenta baixa produtividade para a cultura, 700 a $1.000 \mathrm{~kg} \mathrm{ha}^{-1}$, devido especialmente ao nível tecnológico empregado na sua produção (Borém\& Carneiro, 2013; Ramos et al., 2012; Souza et al., 2016).

Segundo Gonçalves et al. (2017), o aumento da produtividade de feijão será conseguido com o ajuste da relação solo-água-planta para cada variedade desenvolvida nas diferentes regiões e cenários produtivos sociais e econômicos do país. Neste mesmo contexto Souza et al. (2016) comentam sobre a ausência de informações a respeito da influência do manejo da irrigação nas características produtivas da cultura de feijão do gênero Vigna,e citao exemplo da cultivar BRS Pujante, desenvolvida pela Embrapa Semiárido, que apresenta elevado potencial produtivo irrigado (Brito et al., 2009) e não dispõem de registros experimentais conclusivos quanto aos valores de coeficientes de cultura (Kc, especialmente o Kc dual), duração dos estádios fenológicos e estratégias de controle do uso da água.

Atenção deve ser dada a prática da irrigação pois se sabe que esta é a mais demandante em água dentre todas as práticas agrícolas (Mantovani et al., 2009) e a região semiárida, especialmente o polo agrícola de Petrolina/PE é deficitária em recursos hídricos, como verificado por Vianna \&Sentelhas (2014) que em estudo com modelagem para estimativa da produtividade da cana-deaçúcar, apontaram a cidade de Petrolina/PE como a de maior risco de perda de produtividade da cultura associada ao déficit hídrico dentre 30 cidades brasileiras produtoras de cana-de-açúcar.

Desta forma o controle de irrigação e o uso racional da água devem ser imperativos nos cultivos agrícolas. Para tanto o uso da tensiometria e o balanço hídrico climatológico da cultura (ou sequencial)são os métodos mais difundidos em escala de pequeno e médio produtor rural (Lopes et al., 2004).No manejo com tensiômetros, adota-se um valor limite, ou crítico, para o potencial matricial do solo que representa o momento de irrigar, o qual Marouelli (2008) recomenda $-40 \mathrm{kPa}$ para a cultura do feijão;já no manejo climatológico, o balanço hídrico é feito a partir da demanda evapotranspirométrica da região, da demanda hídrica da cultura (em termo de $\mathrm{Kc}$ ) e do conteúdo de água no solo, sempre buscando umidades do solo compreendidas entre a capacidade de campo e a umidade crítica (início do déficit hídrico) (Doorenbos\& Pruitt, 1977).

Allen et al. (1998) e Couto et al. (2015), dentre outros, sugerem o uso do coeficiente de cultura duplo, Kc dual, junção da componente de evaporação do solo (Ke) e da transpiração da cultura, ou basal $(\mathrm{Kcb})$, como forma de melhor determinação da quantidade de água demandada pela planta. Para o feijão "BRS Pujante" esta metodologia de manejo de irrigação ainda é desconhecida. Desta forma, tendo em vista a falta de informações práticas sobre a eficiência destas 
RODRIGUES, J. S.; SILVA, M. G. G.; SOUSA, J. S. C.; SIMÕES, W. L.; LORENZO, V. P.

Tensiometria e balanço hídrico climatológico no manejo de irrigação do feijão-caupi "BRS Pujante

formas de manejo da irrigação para a cultura na região, objetivou-se com este trabalho,avaliar a eficiência produtiva do feijão-caupi cv. BRS Pujante sob manejo da irrigação a partir de tensiômetros e do balanço hídrico climatológico sequencial usando Kc dual.

\section{Material e métodos}

O experimento foi conduzido no campusPetrolina Zona Rural do IFSertão-PE, situado em

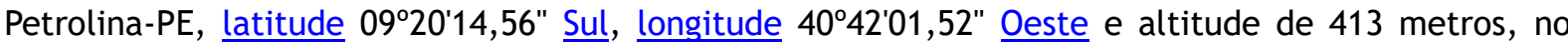
período de setembro a novembro de 2017.

A região apresenta classificação climática de Köppen do tipo BSh, ou seja, semiárido muito quente e com estação chuvosa no verão estendendo-se para o início do outono (Azevedo et al., 2003).

O delineamento experimental foi em blocos casualizados com dois tratamentos: manejos de irrigação a partir do balanço hídrico climatológico da cultura - BHC e tensiométrico - TENS, com 12 blocos (repetições), gerando 24 parcelas experimentais e 11 graus de liberdade para o resíduo.

O solo da área experimental foi classificado como Argissolo Amarelo e apresentava as características químicas e físico-hídricas da Tabela 1.

A adubação foi realizada baseando na análise química do solo (Tabela 1) e no manual de recomendação de adubação para o estado de Pernambuco (Cavalcanti et al., 2008).

Tabela 1.Características químicas e físico-hídricas do solo da área experimental.

\begin{tabular}{|c|c|c|c|c|c|c|c|c|c|c|c|}
\hline $\begin{array}{c}\mathrm{pH} \\
(1: 25)\end{array}$ & $\mathrm{CE}_{\mathrm{es}}$ & $P_{\text {disp. }}$ & K & $\mathrm{Na}$ & $\mathrm{Ca}$ & Mg & Al & $\mathrm{H}+\mathrm{Al}$ & $\mathrm{Dg}$ & $\mathrm{CC}$ & PMP \\
\hline $\mathrm{H}_{2} \mathrm{O}$ & $\mathrm{dS} \mathrm{m}^{-1}$ & $\mathrm{mg} \mathrm{kg}^{-1}$ & & & 19.8. & $\mathrm{mol}_{\mathrm{c}} \mathrm{kg}$ & & & $\mathrm{g} \mathrm{cm}^{-1}$ & & \\
\hline 7,33 & 0,54 & 33,62 & 0,38 & 0,04 & 1,16 & 0,38 & 0,0 & 0,66 & 1,60 & 9,38 & 5,42 \\
\hline
\end{tabular}

Onde: $\mathrm{CE}_{\text {es }}, \mathrm{P}_{\text {disp. }}, \mathrm{K}, \mathrm{Na}, \mathrm{Ca}, \mathrm{Mg}, \mathrm{Al}, \mathrm{H}+\mathrm{Al}, \mathrm{CC}$ e PMP, correspondem a, condutividade elétrica do estrato de saturacão do solo; fósforo disponível; concentração de potássio, sódio, cálcio, magnésio, alumínio, hidrogênio mais alumínio, densidade global, umidade a capacidade de campo e umidade a ponto de murcha permanente, respectivamente.

O sistema de irrigação utilizado foi o gotejamento, com tubogotejador de $16 \mathrm{~mm}$ e emissores espaçados em 0,30 m. Dos testes realizados no sistema obteve-se vazão unitária média de 3,50 $\mathrm{Lh}^{-1}$ à pressão de serviço de $1,00 \mathrm{kgf} \mathrm{cm}^{-2}, 97,70 \%$ de coeficiente de uniformidade de distribuição (CUD) e eficiência de 87,93\% (adotada como 90\% do CUD, Vermeiren \& Jobling, 1997).

O plantio foi realizado por semeadura direto na cova, no dia 10/09/2017, no espaçamento de 1,00 m entre fileiras e 0,20 m entre plantas(densidade de plantio de 50.000 plantas por hectare).

As irrigações foram uniformes nos primeiros 15 dias (estádio fenológico I) para ambos os tratamentos, visando o estabelecimento das plantas em todas as parcelas experimentais. Os tratamentos foram aplicados, portanto, a partir do $16^{\circ}$ dia de ciclo se estendendo até o $75^{\circ}$.

As lâminas de irrigação para o balanço hídrico climatológico da cultura consistiram da reposição da água evapotranspirada pela cultura (ETc), estimada a partir do produto entre a evapotranspiração de referência (ETo), o Kc dual da cultura e o coeficiente de localização (Vermeiren \& Jobling, 1997). 
RODRIGUES, J. S.; SILVA, M. G. G.; SOUSA, J. S. C.; SIMÕES, W. L.; LORENZO, V. P.

Tensiometria e balanço hídrico climatológico no manejo de irrigação do feijão-caupi "BRS Pujante

Para determinação da ETo e do Kc dual da cultura adotou-se os procedimentos e equações descritos por Allen et al. (1998).

As variáveis meteorológicas usadas nos cálculos de manejo da irrigação (Figura 1) foram obtidas diariamente de uma estação agrometeorológica automática, marca Davis, modelo vantage pro 2, localizada a cerca de $900 \mathrm{~m}$ da área experimental.

Figura 1. Variáveis climáticas registradas durante condução do experimento.

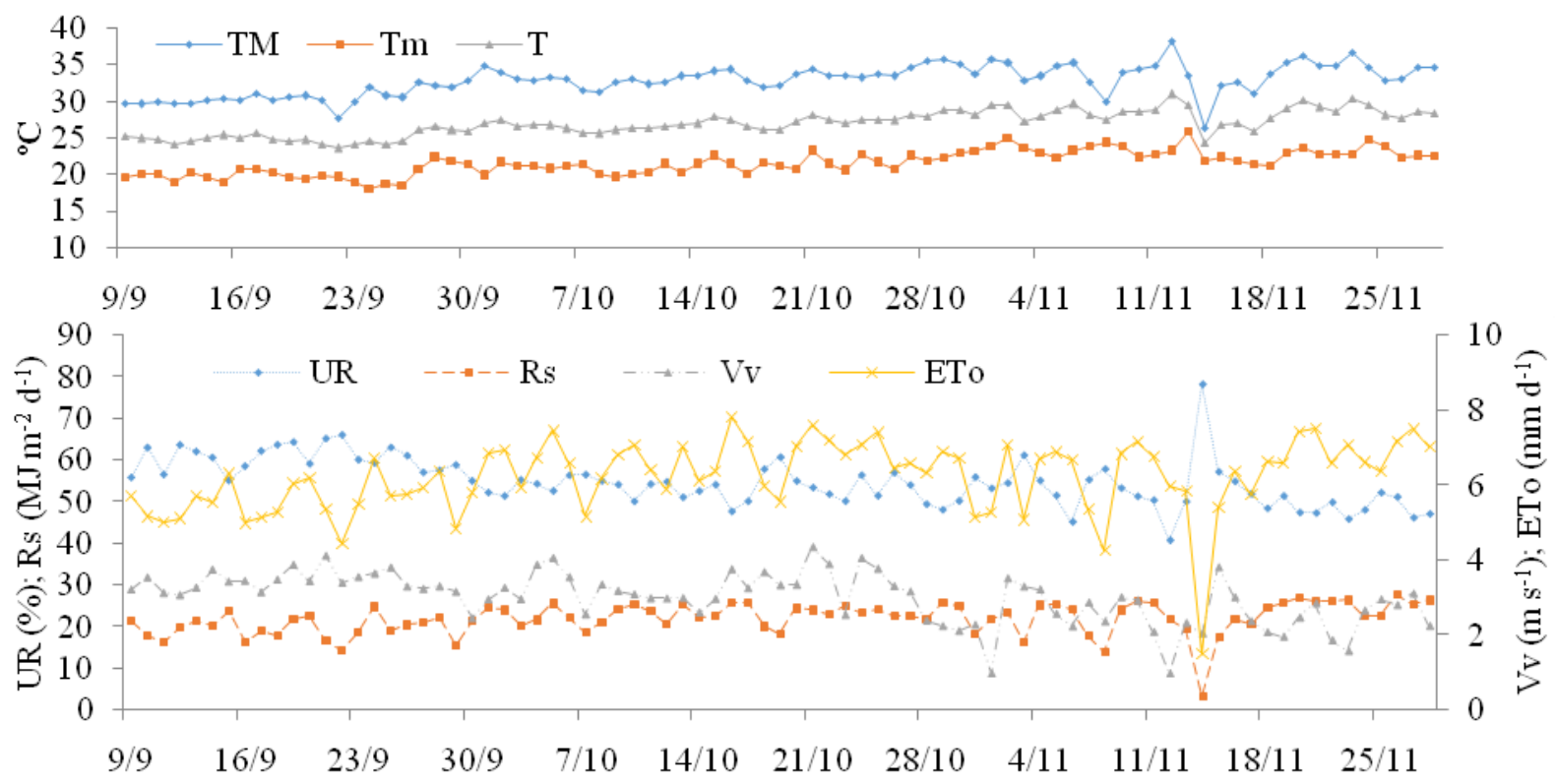

Onde: TM, Tm e T; UR; Rs; Vv e ETo são respectivamente, temperatura máxima, mínima e média do ar;umidade relativa do ar; radiação solar global; velocidade do vento e evapotranspiração de referência. Para o ano de 2017 numa estação meteorológica instalada nas coordenadas geográficas $9^{\circ} 20^{\prime} 4,20^{\prime \prime} \mathrm{S}, 40^{\circ} 41^{\prime} 34,46 " \mathrm{~W}$ e $421 \mathrm{~m}$, Petrolina/PE.

0 monitoramento da umidade do solo foi realizado a partir de tensiômetros de punção instalados nas profundidades 0,20 e $0,40 \mathrm{~m}$ em ambos os tratamentos (BHC e TENS). As leituras foram realizadas três vezes por semana com uso de tensímetro digital, sempre nas primeiras horas da manhã. $O$ potencial matricial do solo $\left(\Psi_{\mathrm{m}}\right)$ era conseguido com o cálculo subtrativo da leitura realizada no tensímetro (em mbar) pela coluna de água no tensiômetro (em $\mathrm{cm}$ de coluna de água).Foram instalados três tensiômetros por parcela, totalizando 72 tensiômetros.

Para o tratamento tensiométrico, as irrigações foram realizadas quando o $\Psi$ mencontrava-se a -40 kPa (Marouelli, 2008) e a umidade do solo era estimada a partir da curva de retenção de água no solo (Figura 2), obtida pelo método das câmaras de pressão de Richards. 0 momento da irrigação bem como a lâmina aplicada, era definido a partir do potencial matricial médio dos tensiômetros a 0,20 m de profundidade. Os demais tensiômetros serviram para estimar percolação de água.

A colheita foi realizada manualmente iniciando-se aos 63 dias após o plantio (DAP), correspondente a 56 dias após a emergência,com quatro repasses aos 66, 69, 75 e 80 DAP sendo que a partir dos 75 DAP as irrigações foram suspensas.

Foi contabilizado o total de graus-dia acumulados (soma térmica) pela cultura, utilizando-se da metodologia de Villa Nova et al. (1972) com temperaturas basais inferior e superior, respectivamente, de 9 e $38^{\circ} \mathrm{C}$ (Farias et al., 2015). 
RODRIGUES, J. S.; SILVA, M. G. G.; SOUSA, J. S. C.; SIMÕES, W. L.; LORENZO, V. P. Tensiometria e balanço hídrico climatológico no manejo de irrigação do feijão-caupi "BRS Pujante

Foram avaliados ainda, número de vagens por planta (NVP), comprimento de vagens (CoV), número de grãos por vagens (NGV), massa de cem grãos (P100), produtividade de grãos secos (PTG), em $\mathrm{kg} \mathrm{ha}^{-1}$, e a eficiência do uso da água (EUA). Esta última foi obtida pela razão entre a PTG e a lâmina de água aplicada $\left(\mathrm{mm} \mathrm{ha}^{-1}\right)$, expressa em $\mathrm{kg} \mathrm{mm}^{-1}$.

Figura 2. Curvas de retenção de água do solo nas profundidades de 0 a $0,20 \mathrm{~m}$ ede 0,20 a 0,40 m.
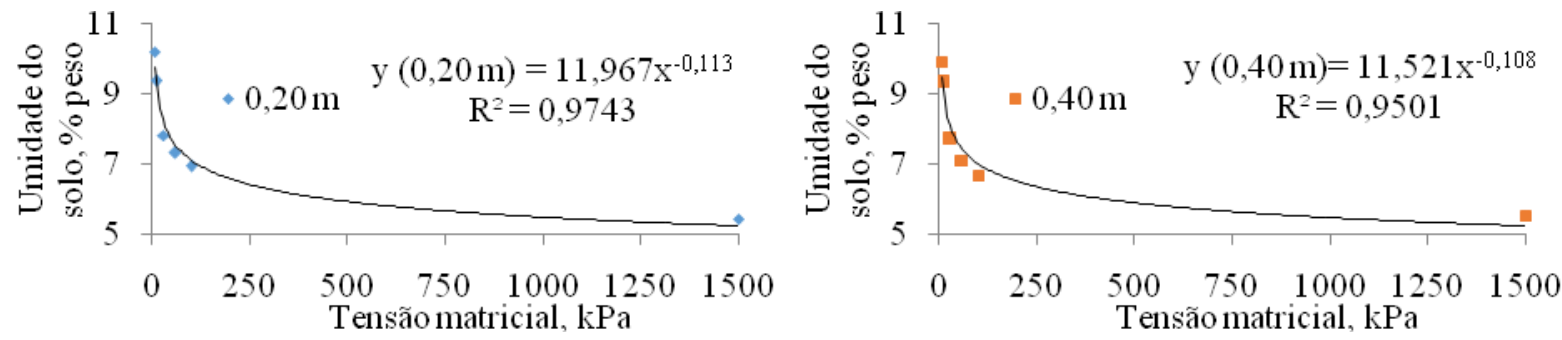

Os resultados foram submetidos à análise de variância pelo teste $\mathrm{F}$ e na presença de efeito significativo foi feita a comparação das médias pelo teste de Tukey a $5 \%$ de probabilidade, a partir do programa SISVAR, versão 5.6 (Ferreira, 2011).

\section{Resultados e discussão}

A duração do ciclo da cultura neste ensaio, 63 a 80 dias (correspondentes a 56 e 63 dias após a emergência, respectivamente), foi similar ao de outras variedades de feijão-caupi, a citar BRS Acauã, BRS Canapu, BRS Guariba, BRS Novaera e BRS Pajeú, que em estudos realizados nas cidades de Juazeiro/BA e Boa Vista/Ro, com sistemas de irrigação e situação climática análogas a este teste, apresentaram ciclos de 63 a 78 dias (Locatelli et al., 2014; Gonçalves et al., 2017).

0 desenvolvimento da cultura ocorreu dentro da faixa de temperatura adequada para o feijoeiro, 9 a $38^{\circ} \mathrm{C}$ (Farias et al., 2015), excedendo a temperatura máxima em apenas um dia (12/11/2017, valor de $38,30^{\circ} \mathrm{C}$, Figura 1), e acumulando o total de 995,95 a 1.344,60 graus-dia no ciclo, respectivamente a $1^{\text {a }}$ e última colheita. Esta faixa de valores é ligeiramente superior a obtida por Farias et al. (2015) para a cultivar BR3 Tracuateua (feijão-caupi), 724,31 a 1.052,97 graus-dia, em Castanhal/PA, com ciclo que variou de 53 a 57 dias a contar da emergência, e Moura et al. (2012) 1.103,50 para a cultivar BR 17 - Gurguéia (feijão-caupi), cultivada em Teresina/PI. Porém, estes últimos consideraram temperatura basal inferior igual a $10^{\circ} \mathrm{C}$ e o ciclo durou 60 dias (com isso em termos de comparação ao ensaio em questão a soma térmica seria de 1.163,50 graus-dia). Estavariável, soma térmica ou graus-dia acumulados, que serve para definir a data de plantio em função da data esperada para colheita, pode apresentar divergências de valores a depender dos fatores adotados. No caso da comparação em curso, tal divergência já era esperada, pois segundo Valera (2017) as temperaturas basais da cultura se alteram no decorrer do ciclo. 0 autor cita o exemplo (para temperatura de base inferior) da pimenta "biquinho" que apresenta valores de 14,8 a $20,2{ }^{\circ} \mathrm{C}$ das fases de transplante-início da floração a frutificação-maturação dos frutos.

Para a análise da demanda hídrica do cultivo, tomando-se o tratamento cujo manejo de 
RODRIGUES, J. S.; SILVA, M. G. G.; SOUSA, J. S. C.; SIMÕES, W. L.; LORENZO, V. P. Tensiometria e balanço hídrico climatológico no manejo de irrigação do feijão-caupi "BRS Pujante

irrigação ocorreu a partir do balanço hídrico climatológico da cultura, observou-se variações na ETcde 1,44 a 9,38 com média de 6,76 $\mathrm{mm} \mathrm{dia}^{-1}$ e no $\mathrm{Kc}$ dual de 0,34 a 1,20 com média de 1,07 (Figura 3). Expandindo a comparando para os valores de Kc dual e Kc único (Allen et al., 1988), nota-se divergência entre eles apenas no início da terceira fase fenológica, que no caso do ensaio ocorreu no $23^{\circ}$ dia após plantio - DAP (com o Kc dual) e com o Kc único só ocorreria no $40^{\circ}$ DAP.

Figura 3. Demanda evapotranspirométrica da cultura durante o experimento.

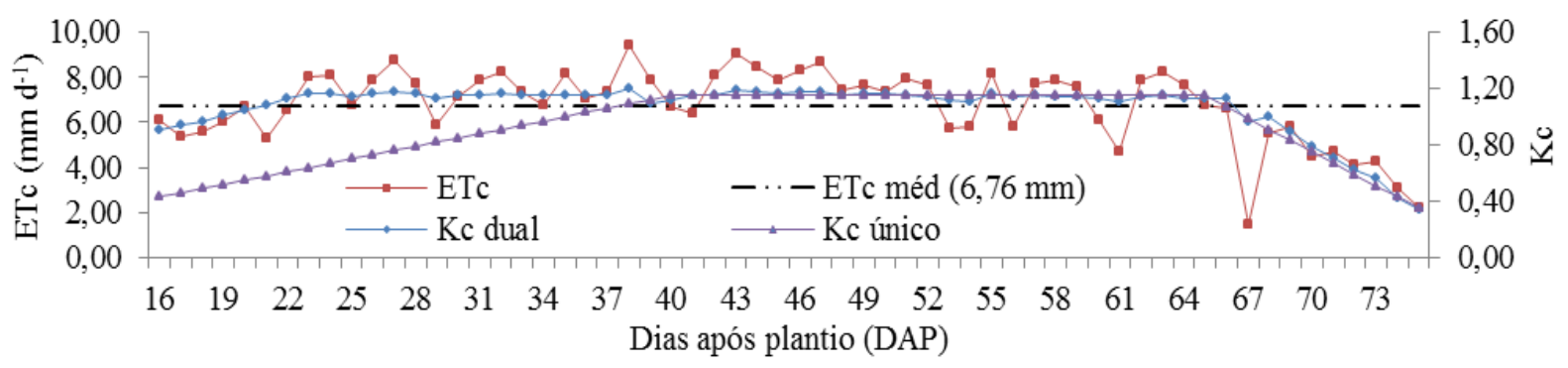

$\mathrm{O}$ fato do Kc dual resultar em valores maiores que o Kc único também foi verificado por Correia et al. (2015) em cultivo de milho no município de Coimbra/MG.Os autores compararam as duas metodologias de determinação do Kc (único e dual) e observaram que as variações entre elas são maiores nas fases inicial e finaldo cultivo e ínfimas no desenvolvimento e frutificação da cultura, tais observações, como pode ser notado na Figura 3, corroboram com os resultados deste ensaio.

As maiores demandas hídricas ocorreram na terceira fase fenológica da cultura, chegando, como já citado a 9,38 mm dia-1(Figura 3) assemelhando-se aovalor encontrado por Silva et al. (2017) para as cultivares BRS Acauã, 8,90 $\mathrm{mm} \mathrm{dia}^{-1}$, e Canapu, 10,90 $\mathrm{mm} \mathrm{dia}^{-1}$.

Os valores de Kc duais obtidos $(0,34$ a 1,20)são aproximados aos apresentados por Doorenbos \& Kassam (1979), 0,30 a 1,20 para feijões; sensivelmente inferiores aos obtidos por Bastos et al. (2008) para a "BRS Guariba", que foi de 0,30 a 1,40, também inferiores aos observados por MurgaOrillo et al. (2016) para o feijão-caupi cv. Novaera, 0,38 a 1,31 e aos de Silva et al. (2017) 0,49 a 1,31 para as cv. Canapu e BRS Acauã. Estas divergências de valores de Kc segundo Silva et al. (2015) são devidas as condições locais e características da cultura, o que reafirma a necessidade de ajustes para casos de novos materiais genéticos e condições de manejo.

Em relação às lâminas de água aplicadas, o tratamento com tensiometria (TENS) gerou consumo total de 183,75 mm contra 405,55 mm para o manejo climatológico (BHC). Uma redução de aproximadamente $55 \%$ de uso de água, que representa $2.218 .000 \mathrm{~L}$ de água por hectare ciclo-1 ${ }^{-1}$ o suficiente para abastecer por um dia uma cidade de aproximadamente 15 mil habitantes (considerando consumo diário percapita de água de 150 L, conforme SABESP, 2012).

Mesmo com esta diferença de lâminas de água, houve semelhança aos dados literários em termos de tipo de manejo de irrigação. Lopes et al. (2004), por exemplo, obtiveram consumo de 263,00 mm de água no manejo tensiométrico para a cultura de feijão comum (ciclo de 96 dias, que em projeção linear para 63 dias seria de 172,60 mm), já Moura et al. (2009) e Souza et al. (2011) alcançaram 449,06 e $448,70 \mathrm{~mm}$, respectivamente, para a cultivar Pujante em trabalho desenvolvido em Petrolina-PE com manejo climatológico. Ramos et al. (2013) obtiveram, para 
RODRIGUES, J. S.; SILVA, M. G. G.; SOUSA, J. S. C.; SIMÕES, W. L.; LORENZO, V. P. Tensiometria e balanço hídrico climatológico no manejo de irrigação do feijão-caupi "BRS Pujante

Teresina-PI, lâminas de 449,00 e $370,00 \mathrm{~mm}$ para as cultivares BRS Guariba e Paraguaçu, respectivamente, também com manejo climatológico, e Kuhn et al. (2016) afirmam que o valor ótimo de lâmina d'água para a cultura do feijoeiro fica entre 250,00 e 500,00 mm.

Ainda com relação à diferença das lâminas, pode-se verificar na Figura 4, que o excesso de água do manejo climatológico só se mostra claramente até o $31^{\circ} \mathrm{DAP}$, onde a tensão matricial do solo para este tratamento $(\mathrm{BCH})$ encontra-se abaixo da tensão de capacidade de campo, indicando percolação de água (Mantovani et al., 2009). Deste momento em diante as tensões (do BCH) se aproximam da linha de capacidade de campo (nos dias seguintes as irrigações), com exceção da parte central da terceira fase fenológica que corresponde ao período de maior demanda hídrica da planta (Allen et al., 1998). Nesta fase, o tempo entre as leitura dos tensiômetros era suficiente para a planta absorver a água da irrigação e elevar a tensão matricial do solo (frisa-se que o monitoramento dos tensiômetros era feita pela manhã antes das irrigações). Pela proximidade das tensões entre os tensiômetros instalados a 20 e $40 \mathrm{~cm}$ de profundidade, e a posição superior à linha de capacidade de campo, evidencia pequena percolação de água no solo em ambos os manejos. 0 motivo das tensões matriciais serem maiores para o manejo tensiométrico está na tensão limite estabelecida.

Figura 4. Tensão matricial no solo em diferentes profundidades $(20$ e $40 \mathrm{~cm})$ e fases fenológicas da cultura do feijão "Pujante" para os tratamentos com manejo de irrigação:A)climatológico ou a partir do balanço hídrico da cultura (BHC) e,B)tensiométrico (TENS).
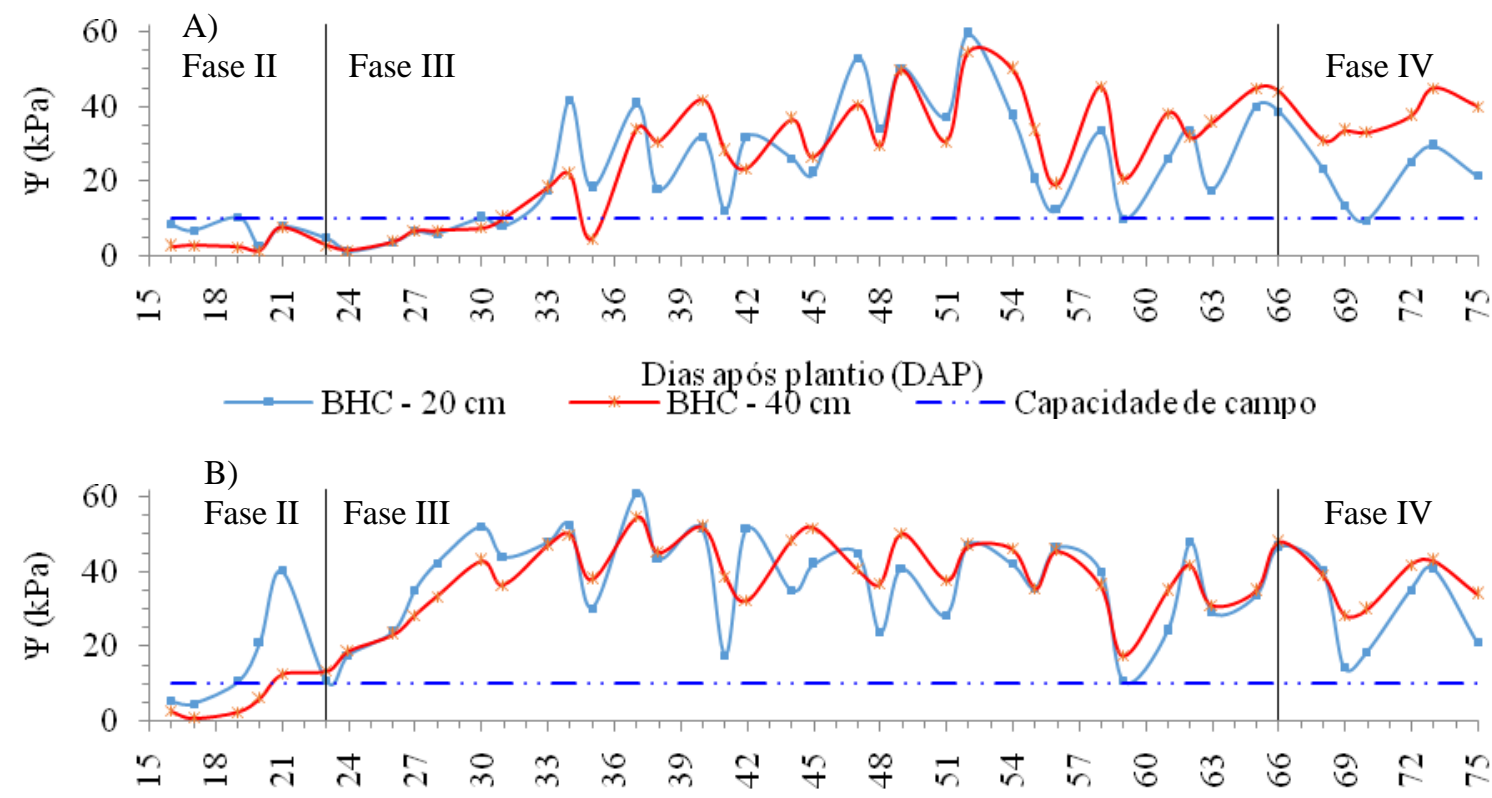

$\longrightarrow$ TENS $-20 \mathrm{~cm}$

Dias após plantio (DAP)

Embora existam, na literatura, poucos estudos sobre o manejo tensiométrico para o cultivo do gênero Vigna, os resultados deste ensaio assemelham-se aos encontrados por Libardi \& Saad (1994) e Lopes et al. (2004) para o cultivo de P. vulgaris irrigados via pivô central, nos quais os tratamentos com manejo climatológico apresentaram os maiores valores de água disponível no solo 
RODRIGUES, J. S.; SILVA, M. G. G.; SOUSA, J. S. C.; SIMÕES, W. L.; LORENZO, V. P. Tensiometria e balanço hídrico climatológico no manejo de irrigação do feijão-caupi "BRS Pujante

em comparação aos tensiométricos. Ferreira (2017) em estudo realizado com diferentes tensões para o feijoeiro observou que nos tratamentos de menor tensão (30 kPa)as plantas receberam lâminas de água mais frequentemente e em menores quantidades, com irrigações diárias na maior parte do ciclo, já para as tensões de 40 e $50 \mathrm{kPa}$ o turno de irrigação chegava adois dias ou mais. Nesta pesquisa as irrigações foram, comumente, diárias para o manejo climatológico e de dois dias no manejo tensiométrico.

No entanto, caso tenha ocorrido estresse hídrico nos tratamentos tensiométricos, este foi moderado já que as tensões ficaram, predominantemente, abaixo dos 50 kPA (Ferreira 2017),e não se observou perdas nos atributos produtivos da cultura (Tabela 2). Esse resultado pode ter ocorrido devido ao fato da planta nessas condições aumentar a eficiência de uso da água (RAMOS et al., 2013). Taiz et al. (2017) explicam que quando ocorre déficit hídrico moderado a taxa fotossintética da folha não é tão responsiva, devido ao fato da fotossíntese apresentar-se menos sensível ao turgor do que a expansão foliar, e assim o $\mathrm{CO}_{2}$ pode ser absorvido por unidade de água transpirada e o fechamento estomático,apesar de inibe a transpiração, não diminui, nestas circunstâncias, as concentrações $\mathrm{CO}_{2}$ intercelulares.

Tabela 2. Resumo da análise de variância para o número de vagens por planta (NVP), comprimento de vagens (CoV), número de grãos por vagens (NGV), peso de cem grãos (P100), produtividade total de grãos (PTG) e eficiência de uso da água (EUA) para o feijão-caupi, cultivar BRS Pujante submetido aos manejos tensiométrico (TENS) e balanço hídrico climatológico (BHC) em Petrolina/PE.

\begin{tabular}{ccccccc}
\hline & \multicolumn{5}{c}{ TESTE F } \\
\cline { 2 - 7 } FV & NVP & CoV $(\mathrm{cm})$ & NGV & P100 $(\mathrm{g})$ & ${\text { PTG }\left(\mathrm{kg} \mathrm{ha}^{-1}\right)}^{\text {EUA }\left(\mathrm{kg} \mathrm{mm}^{-1} \mathrm{ha}^{-1}\right)}$ \\
\hline BLOCO & $0,644^{\mathrm{ns}}$ & $2,404^{\mathrm{ns}}$ & $2,255^{\mathrm{ns}}$ & $1,98^{\mathrm{ns}}$ & $0,602^{\mathrm{ns}}$ & $0,695^{\mathrm{ns}}$ \\
TRAT & $4,665^{\mathrm{ns}}$ & $1,582^{\mathrm{ns}}$ & $0,423^{\mathrm{ns}}$ & $0,67^{\mathrm{ns}}$ & $3,280^{\mathrm{ns}}$ & $64,413^{* *}$ \\
CV $(\%)$ & 16,18 & 3,12 & 4,53 & 6,15 & 17,85 & 19,42 \\
MANEJO & & \multicolumn{5}{c}{ MÉDIA DOS TRATAMENTOS } \\
TENS & $13,02 \mathrm{a}$ & $20,71 \mathrm{a}$ & $12,21 \mathrm{a}$ & $24,50 \mathrm{a}$ & $1.358,67 \mathrm{a}$ & $7,39 \mathrm{a}$ \\
BHC & $15,02 \mathrm{a}$ & $21,04 \mathrm{a}$ & $12,06 \mathrm{a}$ & $24,00 \mathrm{a}$ & $1.550,67 \mathrm{a}$ & $3,82 \mathrm{~b}$ \\
\hline
\end{tabular}

Em que: ${ }^{\text {ns }}$ Não significativo, * significativo 0,05 de probabilidade, ** significativo 0,01 de probabilidade, pelo teste $\mathrm{F}$. Valores seguidos de mesma letra não se diferem estatisticamente ao teste de Tukey a 5\% de probabilidade.

Os indicativos produtivos apresentados na Tabela 2 se equiparam aos obtidos por Moura et al. (2009) trabalhando com a mesma cultivar, sistema de irrigação e munícipio, no qual os autores obtiveram para o NVP o valor de 15,50, 22,39 cm para a CoV e 11,73 para o NGV. E Santos et al. (2007), alcançaram $18,40 \mathrm{~cm}$ para o CoV, 9,20 para o NGV e 24,80 g para o P100, também para a cultivar BRS Pujante.

Com relação à produtividade(PTG, Tabela 2) o manejo climatológico resultou em 1.550,67 kg $\mathrm{ha}^{-1}$, que éinferior aos $1.824,12 \mathrm{~kg} \mathrm{ha}^{-1}$ obtidospor Moura et al. (2009) para a mesma variedade, porém, alcançados com 449,06 mm contra os 405,55 mm deste trabalho. Contudo, superior aos alcançados por Souza et al. (2011) e Brito et al. (2012), também para a variedade BRS Pujante, 1.374,70e 1.422,50 $\mathrm{kg} \mathrm{ha}^{-1}$, respectivamente e aos de Locatelli et al. (2014) para as cultivares BRS Guariba,BRS Novaera e BRS Pajeú, 1.170,19, 1.308,85 e 1.495,07 kg ha-1, respectivamente, para cultivo em Boa Vista/RO. Superior ainda as produtividades médias obtidas por Dutra et al. (2015) para as cultivares BRS Guariba $\left(1.282,10 \mathrm{~kg} \mathrm{ha}^{-1}\right)$, BR17 Gurguéia $\left(1.200,12 \mathrm{~kg} \mathrm{ha}^{-1}\right)$ e BRS Marataoã 
RODRIGUES, J. S.; SILVA, M. G. G.; SOUSA, J. S. C.; SIMÕES, W. L.; LORENZO, V. P. Tensiometria e balanço hídrico climatológico no manejo de irrigação do feijão-caupi "BRS Pujante

\section{$\left(1.436,06 \mathrm{~kg} \mathrm{ha}^{-1}\right)$.}

Vale destacar que embora não se encontre informações acerca de produtividades para o manejo de irrigação com tensiometria no cultivo do gênero Vigna, a produtividade de grãos colhida $\left(1.358,67 \mathrm{kgha}^{-1}\right)$ apresenta-se aproximada aos valores acima mencionados para o manejo por balanço hídrico. $E$ em termos de uso eficiente da água (EUA), única variável com diferença estatística, este manejo sobrepôs-se ao climatológico em 1,93 vezes (Tabela 2) sem redução significativa de produtividade. Arf et al. (2004) já enfatizava que em menores lâminas de irrigação é possível se obter produtividades de grãos semelhantes aos de laminas maiores, proporcionando assim, maiores receitas e menores desperdícios de água. Ramos et al. (2012) verificou que o consumo médio de energia elétrica por mm de irrigação, em sistema de aspersão convencional, é de cerca de 6,52 kWh ha-1 em Teresina/PI e para o feijão ("BRS Guariba" e "BRS Paraguaçu") as lâminas que maximizam as receitas são de 290 a $363 \mathrm{~mm}$ considerando os preços médios da região (energia elétrica e do produto feijão). Tomando está observação por base, e considerando que a aplicação de 183,75 ou $405,55 \mathrm{~mm}$ resultam na mesma produtividade, pode-se inferir ao manejo tensiométrico as maiores chances de sucesso econômico como o cultivo de feijão-caupi "BRS Pujante" irrigado.

Observa-se ainda que se o experimento tivesse sido conduzido com o Kc único a produtividade média da cultura provavelmente não teria sido diferente do que foi alcanço com o Kc dual já que a reduzida diferença de valores do Kc único não chegaria a provocar lâmina de irrigação inferior ao do tratamento com o manejo tensiométrico e este, em termos de produção, não gerou diferença estatística ao proporcionado pelo manejo climatológico.

\section{Conclusões}

O manejo da irrigação com o uso de tensiômetros proporcionou menor disponibilidade de água no solo em comparação ao manejo climatológico, porém, gerou maior eficiência de uso da água com economia de até $55 \%$ sem afetar a produtividade de grãos.

Não houve diferença estatística entre os tratamentos para outras variáveis de produção do feijão.

\section{Referências}

ALLEN, R.G.; PEREIRA, L.S. \&RAES, D. Cropevapotranspiration. Guidelines for computing crop water requirements. Roma, FAO, 1998. 301p. (Irrigation and Drainage, Paper 56).

ARF, O; RODRIGUES, R.A.F; SÁ, M.E; BUZETTI, S. \& NASCIMENTO, V. Manejo do solo, água e nitrogênio no cultivo de feijão. Pesquisa Agropecuária Brasileira, 39:131-138, 2004.

AZEVEDO, C.V.G.; RIBEIRO, T.; SILVA, D.A.; CARBONELL, S.A.M \& CHIORATO, A.F. Adaptabilidade, estabilidade e resistência a patógenos em genótipos de feijoeiro. Pesq. agropec. bras., 50:912-922, 2015.

AZEVEDO, P.V.; SILVA, B.B. \& SILVA, V.P.R. Walter requirements of irrigated mango orchards in 
RODRIGUES, J. S.; SILVA, M. G. G.; SOUSA, J. S. C.; SIMÕES, W. L.; LORENZO, V. P.

Tensiometria e balanço hídrico climatológico no manejo de irrigação do feijão-caupi "BRS Pujante

Northeast Brazil. Agricultural Water Management, 58:241-245, 2003.

BASTOS, E.; FERREIRA, V.; SILVA, C. \& ANDRADE JÚNIOR, A. Evapotranspiração e coeficiente de cultivo do feijão-caupi no Vale do Gurguéia, Piauí. Irriga, 13:182-190, 2008.

BORÉM, A. \& CARNEIRO, J.E.S. A cultura. In: VIEIRA, C.; PAULA JUNIOR, T.J. \& BORÉM, A. Feijão. Ed. 2. Viçosa, UFV, 2013. p.13-18.

BRITO, L.T.L.; CAVALCANTI, N.B.; SILVA, A.S. \& PEREIRA, L.A. Produtividade da água de chuva em culturas de subsistência no semiárido pernambucano. Eng. Agríc., 32:102-109, 2012.

BRITO, L.T.L; CAVALCANTI, N.B.; SILVA, A.S. \& PEREIRA, L.A. Produtividade da água de chuva na cultura do feijão caupi em condições semiáridas. In: $7^{\circ}$ SIMPÓSIO BRASILEIRO DE CAPTAÇÃO E

MANEJO DE ÁGUA DA CHUVA, 7, Caruaru/PE, 2009. Anais. Caruaru/PE, ABCMAC, 2009.

CAVALCANTI, F.J.A. coord. Recomendações de adubação para o Estado de Pernambuco: segunda aproximação. 3 ed. Recife, IPA, 2008. 212p.

CONAB. Companhia Nacional de Abastecimento.Perspectiva para a agropecuária, safra de 2017/2018. Disponível em: <https://www.conab.gov.br/>. Acesso em: 12 Set. 2018.

CORREIA, C.C.S.A.; SILVA, E.P.; MANTOVANI, E.C. \& DELAZARI, F.T. Estudo comparativo do coeficiente de cultura simples e duplo no município de Coimbra/MG. In: III INOVAGRI INTERNATIONAL MEETING, 3, Fortaleza/CE, 2015, Anais. INOVAGRI, 2015.

COUTO, J.P.C.; CAVALCANTE, A.R.; SILVA, N.D. \& BORGES, T.K.S. Estimativa diária da evapotranspiração e do coeficiente de cultivo simples e dual para a cultura da beterraba. In: XXV CONGRESSO NACIONAL DE IRRIGAÇÃO E DRENAGEM, 25, 2015, São Cristóvão/SE. Anais. CONIRD, São Cristóvão/SE, 2015.

DOORENBOS, J. \& PRUITT, W.O. Necessidades hídricas das culturas. Campina Grande/PB, UFPB, 1977. 204p. (Irrigação e Drenagem, 24).

DOORENBOS, J. \&KASSAM, A.H. Yieldesponsetowater. Roma, FAO, $1979.193 p$. (IrrigationandDrainagePaper, 33).

DUTRA, A.F.; MELO, A.S.; FILGUEIRAS, L.M.B.; SILVA, A.R.F.; OLIVEIRA, I.M. \& BRITO, M.E.B. Parâmetros fisiológicos e componentes de produção de feijão-caupi cultivado sob deficiência hídrica. Revista Brasileira de Ciências Agrárias, 10:189-197, 2015.

FARIAS, V.D.S; COSTA, D.L.P.; SOUZA, P.J.O.P.; TAKAKI, A.Y. \&LIMA, M.J.A. Temperaturas basais e necessidade térmica para o ciclo dedesenvolvimento do feijão-caupi. Enciclopédia Biosfera, 11:1781-1792, 2015.

FERREIRA, D.F. Sisvar: a computer statistical analysis system. Ciência Agrotecnologia, 35:1039-1042, 2011.

FERREIRA, L.D. Resposta do feijoeiro irrigado sob diferentes tensões de água no solo. Alegrete/RS, IFFarropilha/UNIPAMPA, 2017. 52.p (Trabalho de Conclusão de curso de bacharel em Engenharia Agrícola). 
RODRIGUES, J. S.; SILVA, M. G. G.; SOUSA, J. S. C.; SIMÕES, W. L.; LORENZO, V. P.

Tensiometria e balanço hídrico climatológico no manejo de irrigação do feijão-caupi "BRS Pujante

FERREIRA, N.M.; MESQUITA, E.F.; SÁ, F.V.S.; BERTINO, A.M.P.; PAIVA, E.P. \& FARIAS, S.A.R. Crescimento e produção da mamoneira BRS Paraguaçu sob irrigação, cobertura do solo e adubação orgânica. Revista Brasileira de Engenharia Agrícola e Ambiental, 19:857-864, 2015.

GOMES, E. R.; COSCOLIN, R.B.S.; LIMA, J.; ZUÑIGA, E.A.; MACHUCA, E.A. \& BROETTO, F. Utilização de sensor e tensiômetro no monitoramento da umidade do solo na cultura do feijoeiro sob deficiência hídrica. Revista Brasileira de Agricultura Irrigada, 11:2076-2083. 2017.

GONÇALVES, I.S.; SILVA, R.R.; OLIVEIRA, G.M.; SANTIAGO, E.J.P. \& OLIVEIRA, V.E.A. Características fisiológicas e componentes de produção de feijão caupi sob diferentes lâminas de irrigação. Journal of Environmental Analysis and Progress, 2:320-329, 2017.

KUHN, L.J.; CHECHI, L.; FERNANDES, F.F.; FORTUNA, V.; ALMEIDA, P.M. \& PIAZZETTA, H.V.L. Manejo da irrigação no desempenho agronômico da cultura do feijão. In: VI JORNADA DE INICIAÇÃO CIENTÍFICA E TECNOLÓGICA, 6, 2016, Chapecó/SC. Anais. JORNADA DE INICIAÇÃO CIENTíFICA E TECNOLÓGICA Chapecó/SC, 2016.

LIBARDI, P.L. \& SAAD, A.M. Balanço hídrico em cultura de feijão irrigada por pivô central em latossolo roxo. Revista Brasileira de Ciência do Solo, 18:529-32, 1994.

LOCATELLI, V.E.R.; MEDEIROS, R.D.; SMIDERLE, O.J.; ALBUQUERQUE, J.A.A.; ARAÚJO, W.F. \& SOUZA, K.T.S. Componentes de produção, produtividade eeficiênciada irrigação do feijão-caupi no cerrado de Roraima. Revista Brasileira de Engenharia Agrícola e Ambiental, 18:574-580, 2014.

LOPES, A.S.; PAVANI, L.C.; CORÁ, J.E.; ZANINI, J.R. \& MIRANDA, H.A. Manejo da irrigação (tensiometria e balanço hídrico climatológico) para a cultura do feijoeiro em sistemas de cultivo direto e convencional. Engenharia Agrícola, 24:89-100, 2004.

MANTOVANI, E.C.; BERNARDO, S. \& PALARETTI, L.F. Irrigação: princípios e métodos. 3 ed. Viçosa, UFV, 2009. 355p.

MAROUELLI, W.A. Tensiômetro para o controle de irrigação em hortaliças. 1.ed. Brasília/DF, Embrapa Hortaliças, 2008. 15p. (Circular Técnica 57).

MOURA, J.Z; PÁDUA, L.E.M.; MOURA, S.G.; TORRES, J.S. \& SILVA, P.R.R.; Escala de desenvolvimento fenológico e exigência térmica associada a graus-dia do feijão-caupi. Revista Caatinga, 25:66-71, 2012.

MOURA, M.S.B.; SOUZA, L.S.B.; SILVA, T.G.F.; BRANDÃO. E.O. \& SOARES, J.M. Efeito da lâmina de irrigação na produtividade do feijão-caupi no semiárido brasileiro. In: CONGRESSO BRASILEIRO DE ENGENHARIA AGRICOLA, 38, 2009, Juazeiro/BA, Anais. CONBEA, Juazeiro/BA, 2009.

MURGA-ORRILLO, H.; ARAUJO, W.F.; ROCHA, P.R.R.; SAKAZAKI, R.T.; DIONISIO, L.F.S. \& VARGAS, A.R.P. Evapotranspiração e coeficiente de cultivo do feijão-caupi cultivado em solo do cerrado submetido à cobertura morta. Irriga, 21:172-187, 2016.

RAMOS, H.M.M.; BASTOS, E.A.; ANDRADE JÚNIOR, A.S. \& CARDOSO, M.J. Eficiência do uso da água e produtividade de grãos do feijão-caupi sob diferentes regimes hídricos. In: III Congresso Nacional de Feijão-Caupi, 3, Recife-PE. Anais. CONAC, Recife/PE, 2013.

RAMOS, H.M.M.; BASTOS, E.A.; ANDRADE JÚNIOR, A.S. \& MAROUELLI, W.A. Estratégias ótimas de irrigação do feijao-caupi para produção de grãos verdes. Pesquisa Agropecuária Brasileira, 47:576583, 2012. 
SABESP. Companhia de Saneamento Básico do Estado de São Paulo. Norma Técnica Sabesp NTS 181. Dimensionamento do ramal predial de água, cavalete e hidrômetro - Primeira ligação. 3.ed. SABESP, São Paulo. 26p.

SANTOS, C.A.F.; SANTOS, I.C.N.; RODRIGUES, M.A. Feijão-caupi BRS Pujante: cultivar para áreas irrigadas e de sequeiro do vale do São Francisco. 1.ed. Petrolina/PE, Embrapa Semiárido, 2007. 2p. (Folder).

SILVA, R.R.; GONÇALVES, S.I.; PEREIRA, A.V.A.; OLIVEIRA, G.M.; FERRAZ, A.L.F. \& OLIVEIRA, V.E. Consumo hídrico do feijão caupi no Submédio do Vale do São Francisco. In: IV INOVAGRI INTERNATIONAL MEETING, 4. Fortaleza/CE, 2017. Anais. INOVAGRI, Fortaleza/CE, 2017.

SILVA, R.R.; SANTOS, I.M.S.; OLIVEIRA, G.M.; CARVALHO, A.R.P.; SANTOS JUNIOR, P.P. \& GONÇALVES, I.S. Evapotranspiração e coeficiente de cultura para melancia. Bras. Agric. Irr. 09:392- 399, 2015.

SOUZA, L.S.B.; MOURA, M.S.B.; SEDIYAMA, G.C. \& SILVA, T.G.F. Eficiência do uso da água das culturas do milho e do feijão-caupi sob sistemas de plantio exclusivo e consorciado no semiárido brasileiro. Bragantia, 70:715-721, 2011.

SOUZA, T.M.A.; SOUZA, T.A.; SOUTO, L.S.; SÁ, F.V.S.; PAIVA, E.P. \& MESQUITA, E.F. Água disponível e cobertura do solo sob o crescimento inicial do feijão-caupi cv. BRS Pujante. Revista Brasileira de Agricultura Irrigada, 10:598-604, 2016.

TAIZ, L.;ZEIGER,E.; MØLLER,I.M. \& MURPHY, A. Fisiologia e desenvolvimento vegetal. 6.ed. Porto Alegre/RS, Artmed, 2017. 858p.

VALERA, O.V.S. Temperatura base, soma térmica, plastocrono e duração das fases fenológicas de cultivares de pimenta biquinho. Frederico Westphalen/RS, UFSM, 2017. 70p. (Dissertação de mestrado em Agronomia).

VERMEIREN, G.A. \& JOBLING, G.A. Irrigação localizada. Campina Grande/PB, UFPB, 1997, 184p. (Estudos FAO: Irrigação e Drenagem, 36).

VIANNA, M. S.; SENTELHAS, P. C. Simulação do risco de déficit hídrico em regiões de expansão do cultivo de cana-de-açúcar no Brasil. Pesquisa Agropecuária Brasileira, 49:237-246, 2014.

VILLA NOVA, N.A.; PEDRO JÚNIOR, M.J.; PEREIRA, A.R.\& OMETTO, J.C. Estimativa de graus-dia acumulados acima de qualquer temperatura base em função das temperaturas máxima e mínima. Ciência da Terra, São Paulo, 30:01-08, 1972. 